\title{
A Report Card on Early Childhood Development
}

Child well-being is multidimensional. This chapter summarizes the evidence on the health, nutrition, cognitive, language, socioemotional, and motor development of young children in Latin America and the Caribbean. These measures are important in their own right, and because of their implications for long-term productivity and growth in the region. Where possible, comparisons across countries, changes over time, and differences within countries, especially by wealth or parental education-so-called socioeconomic gradientsare made to provide an added dimension to the description, and a clearer picture of the state of well-being of the region's children.

\section{Just What the Doctor Ordered: Improved Child Health and Nutrition}

In both developed and developing countries, low birth weight (less than 2,500 grams) has been associated with worse health and development outcomes in childhood, learning problems and poor performance in school, an increase in a number of chronic health conditions in adulthood and old age, and worse labor market outcomes. ${ }^{1}$ Low birth weight is an indication of constraints in fetal nutrition (as can be caused by poor nutrition of the mother, infection, or smoking or drinking during pregnancy) or of prematurity (Kramer 1987, 2003).

Two recent papers report compelling evidence from Chile. The first of these (Bharadwaj, Eberhard, and Neilson 2014) finds that low birth weight (less than 2,500 grams) or very low birth weight (less than 1,500 grams) babies have test scores in math that are substantially lower in childhood and up to early adolescence. A companion 
paper (Bharadwaj, Løken, and Neilson 2013) exploits the fact that, in Chile (as is the case in many other countries), babies below the threshold for very low birth weight are eligible for special care in a neonatal intensive care unit. Babies whose weight was just below the cutoff (and who were therefore eligible for special care) were 4.4 percentage points less likely to die in their first year than those whose weight was just above the cutoff (and who were therefore ineligible for care). Moreover, between first and eighth grades, those whose weight at birth was just below the cutoff have test scores that are on average 0.15 standard deviations higher than those whose weight was just above. Taken together, these two papers with Chilean data make clear that low birth weight can have serious, negative consequences for child health and development, but that early intervention can mitigate these effects, at least in part. $^{2}$

\section{Box 2.1 Understanding Standard Deviations}

Outcomes used to measure child well-being are not all in the same metric. Height is measured in centimeters and weight in kilograms. Test scores are measured in integers and each test has a different mean and standard deviation that is arbitrarily chosen by the test designers (e.g., the Peabody Picture Vocabulary Test [PPVT] has a mean of 100 and a standard deviation of 15). To express the myriad of measures into a common metric, researchers use a simple statistical technique. They subtract the mean from the observed outcome measure and divide this difference by the standard deviation of the distribution. These standardized measures all have a mean of zero and a standard deviation of one in the population.

People usually refer to differences in outcomes and gains from programs in terms of standard deviations. In a standardized variable a unit change in the outcome is equivalent to a change in one standard deviation. How can we interpret what a gain in one standard deviation implies? This very much depends on how the outcome variable is distributed in the population. If the distribution of test scores has a bell-shape (i.e., has a normal distribution), a gain of one standard deviation will take someone performing at the bottom 2.5 th percentile of the distribution (where there are very few individuals in the population) to the 17th percentile. Because, there are more people concentrated toward the middle in a bell-shaped distribution (rather 
than uniformly distributed), a one standard deviation increase for someone at the 50th percentile produces a larger percentile gain than for someone at the bottom or top of the distribution.

There is also an often used convention in the psychology literature that classifies program gains of around 0.2 of a standard deviation as small, 0.5 as moderate, and 0.8 as large (Cohen 1969). This does not provide guidance for policy choice, however, as programs with small effects can also have lower costs (see McCartney and Rosenthal 2000). A thorough discussion of the cost-benefit analysis strategy for program choice is provided in Chapter 6.

Estimates of the proportion of all births that are low birth weight for Latin America and the Caribbean reveal large differences across countries (see Table 2.1). In Cuba and Chile, about 1 in 20 babies is born with low birth weight; in Colombia and Mexico, this proportion is about 1 in 10; and in Haiti, almost 1 in 4 . For the region as a whole, 9 percent of babies are born with low birth weight, substantially below the level for countries in Africa (11-14 percent) and, especially, South Asia (28 percent). In some countries in Latin America and the Caribbean, the proportion of low birth weight babies has been increasing, especially among women with higher education levels. This result, which at first blush appears to be paradoxical, is a consequence of the fact that more premature babies who would have died in earlier years now survive (see Box 2.2 for evidence from Colombia).

\section{Table 2.1 Low Birth Weight}

Country

Percentage of children

Latin America and Caribbean

Antigua and Barbuda (2011) 6

\begin{tabular}{lr} 
Argentina (2011) & 7.2 \\
\hline
\end{tabular}

Bahamas (2011) 11.6

Barbados (2011) $\quad 11.5$

Belize (2011) 11.1

Bolivia (2008) 6

$\begin{array}{ll}\text { Brazil (2011) } & 8.5\end{array}$

Chile (2011) $\quad 5.9$

$\begin{array}{ll}\text { Colombia (2012) } & 9.5\end{array}$ 
Table 2.1 Continued

\begin{tabular}{|c|c|}
\hline Country & Percentage of children \\
\hline Costa Rica (2012) & 7.3 \\
\hline Cuba (2012) & 5.2 \\
\hline Dominica (2011) & 10.8 \\
\hline Dominican Republic (2007) & 11 \\
\hline Ecuador (2012) & 8.6 \\
\hline El Salvador (2011) & 8.7 \\
\hline Grenada (2011) & 8.8 \\
\hline Guatemala (2008-09) & 11.4 \\
\hline Guyana (2009) & 14.3 \\
\hline Haiti (2012) & 23 \\
\hline Honduras (2011-12) & 9.9 \\
\hline Jamaica (2011) & 11.3 \\
\hline Mexico (2012) & 9.15 \\
\hline Nicaragua (2011) & 7.6 \\
\hline Panama (2011) & 8.3 \\
\hline Paraguay (2009) & 6.3 \\
\hline Peru (2011) & 6.9 \\
\hline Saint Kitts and Nevis (2011) & 10.4 \\
\hline Saint Lucia (2011) & 10.1 \\
\hline Saint Vincent and the Grenadines (2011) & 10.6 \\
\hline Suriname (2010) & 13.9 \\
\hline Trinidad and Tobago (2011) & 11.9 \\
\hline Uruguay (2012) & 8.1 \\
\hline Venezuela (2011) & 8.6 \\
\hline \multicolumn{2}{|l|}{ Regional averages (2009-13) } \\
\hline Sub-Saharan Africa & 13.05 \\
\hline Eastern and Southern Africa & 11.26 \\
\hline West and Central Africa & 14.18 \\
\hline Middle East and North Africa & - \\
\hline South Asia & 27.76 \\
\hline East Asia and Pacific & - \\
\hline Latin America and Caribbean & 9.02 \\
\hline $\mathrm{CEE} / \mathrm{CIS}$ & 6.12 \\
\hline Least developed countries & 13.71 \\
\hline World & $15.83^{*}$ \\
\hline
\end{tabular}

Notes: Percentage of infants weighing less than 2,500 grams at birth. For Bolivia and Dominican Republic, data refer to years 2009-13. Such data are not included in the calculation of regional and global averages, with the exception of 2005-06 and 2007-08 data from India, Central and Eastern Europe and the Commonwealth of Independent States (CEE/CIS) .* Excludes China.

Source: Data and Analytics Section; Division of Data, Research and Policy, UNICEF. Basic Health Indicators 2010 for Paraguay; Colombia National Statistics System for Colombia; Demographic and Health Surveys (DHS) for Dominican Republic, Bolivia, Guyana, Honduras, and Haiti; Encuesta Nacional de Salud Materno Infantil (ENSMI) for Guatemala; Multiple Indicator Cluster Survey (MICS) for Suriname, Belize; Ministry of Health for Brazil, Argentina, Costa Rica, El Salvador, Cuba, Uruguay, and Nicaragua; National Institute of Statistics (INE) for Chile; National Institute of Census and Statistics (INE) for Chile; Other National Survey, National Institute of Public Health for Mexico; Pan American Health Organization (PAHO), Health Situation in the Americas: Basic indicators 2013 for Antigua and Barbuda, Bahamas, Barbados, Dominica, Grenada, Jamaica, Panama, Peru, Saint Kitts and Nevis, Saint Lucia, Saint Vincent and the Grenadines, Trinidad and Tobago; Sistema de Indicadores Sociales de Venezuela for Venezuela. 


\section{Box 2.2 Changes in Prematurity and Birth Weight in Colombia}

The proportion of low birth weight babies has been on the rise in some countries in Latin America and the Caribbean. Figure B2.1 is based on vital registration data on all births in Colombia between 1998 and 2008. Panels a and b show that mean birth weight declined, and the proportion of babies with low birth weight increased between 1998 and 2008. The decline in birth weight is particularly sharp for babies born to women with university education-indeed, babies born to women with more education are now substantially more likely to be below the cutoff for low birth weight than those born to women with less education.

At first blush, this result appears to be paradoxical. Plausibly, however, it is a consequence of the fact that an increasing fraction of all births are preterm (births that occur before the thirty-eighth week of pregnancy), in particular among women with higher levels of education (see Figure B2.1, panel c). In the past, many of these "additional" low birth weight babies would have been miscarriages or would not have been born alive.

\section{Figure B2.1 Weight at Birth, Colombia}

a. Weight at Birth, according to Mother's Education

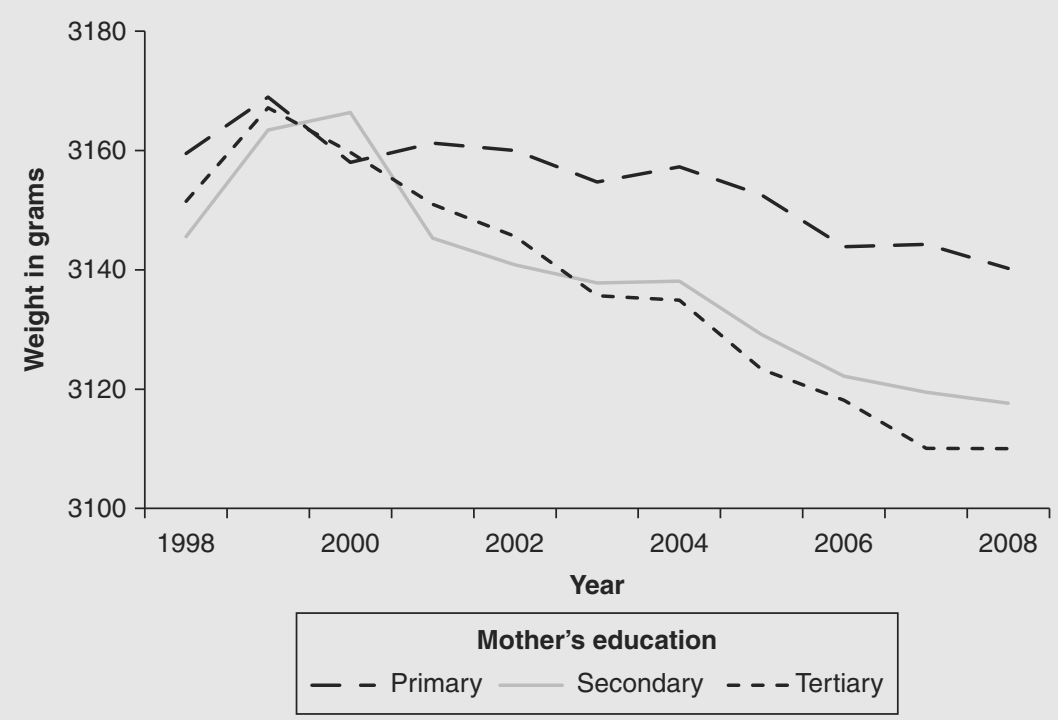


b. Proportion with Low Birth Weight, according to Mother's Education

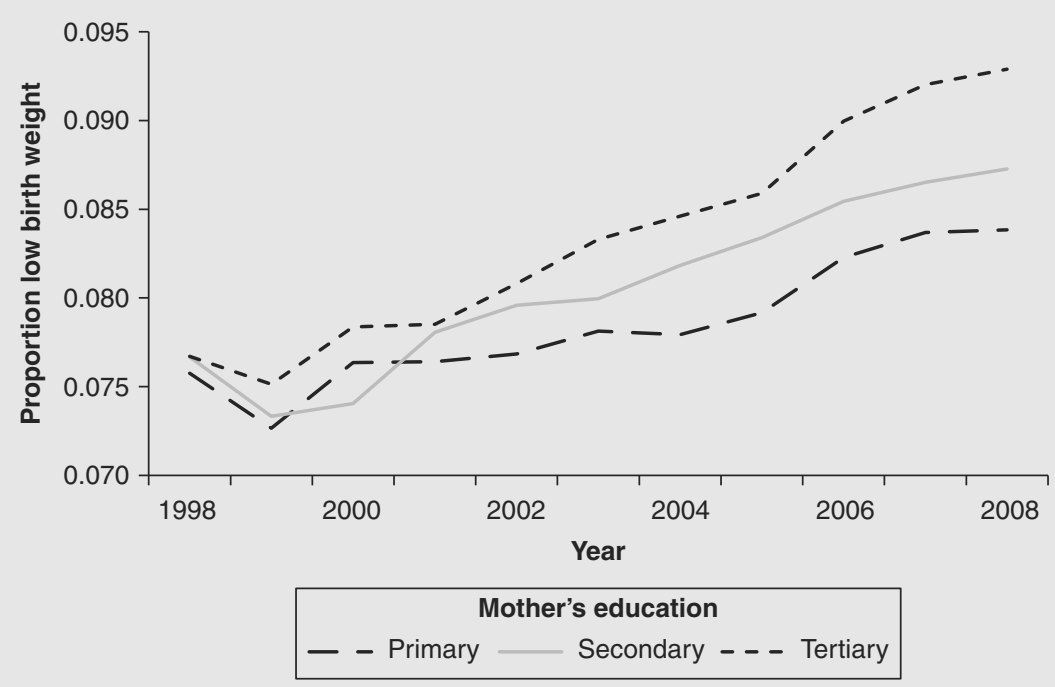

c. Proportion of Premature Births, according to Mother's Education

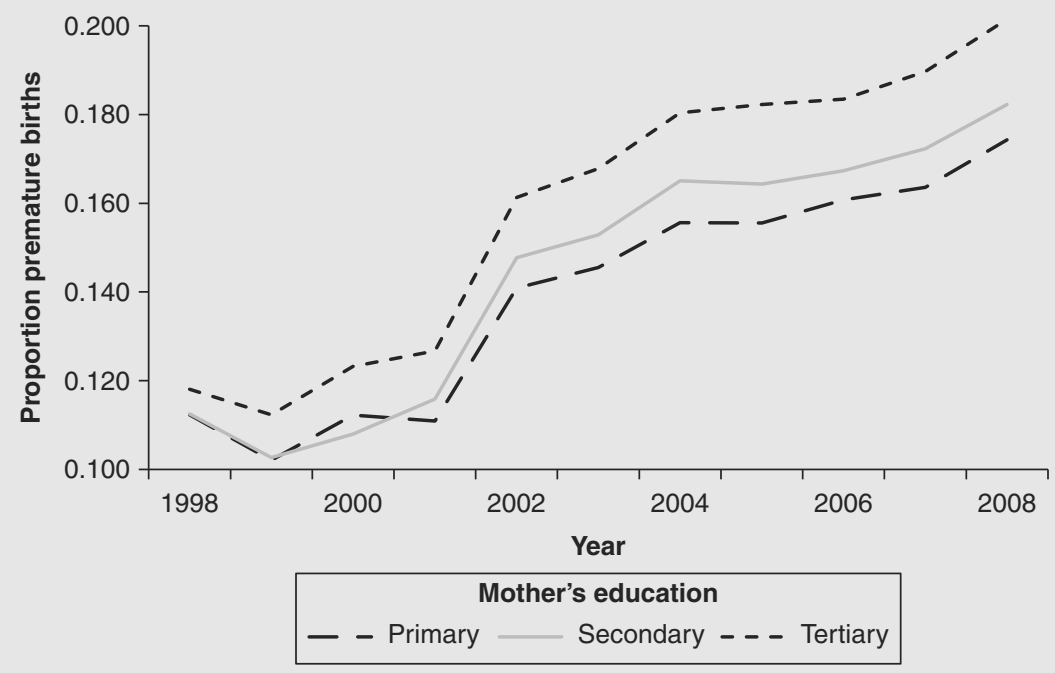




\section{d. Changes in Proportion Low Birth Weight for Mothers with Tertiary Education}

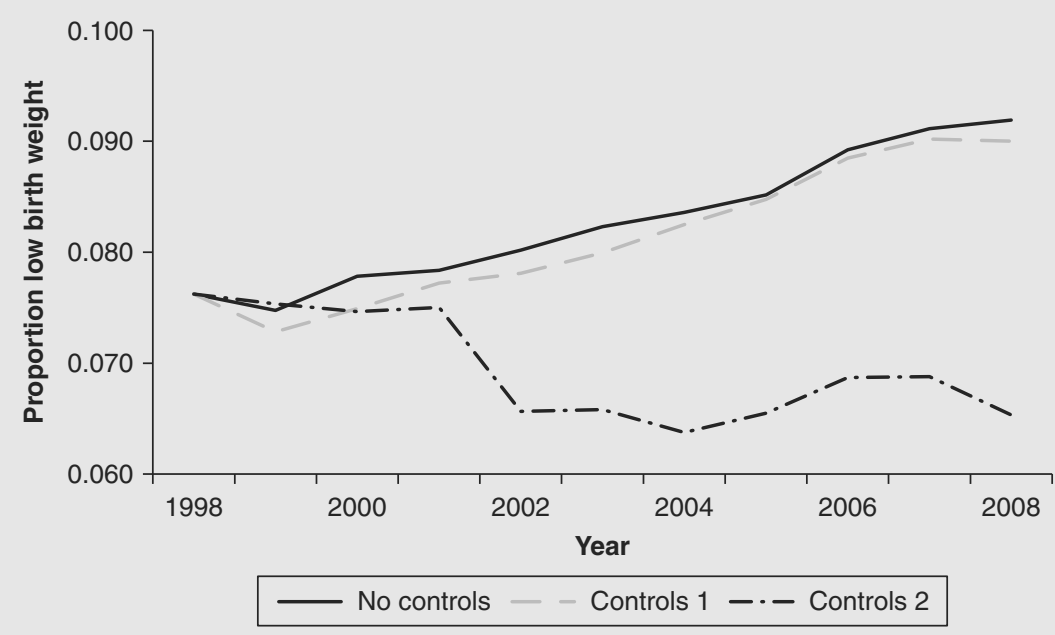

Source: Vital registration data, Colombia 1998-2008.

One way to test this is by controlling for prematurity, and seeing whether the increase in the proportion of low birth weight babies is still apparent. The results from this exercise can be found in panel $\mathrm{d}$, for women with tertiary education (for whom the decline in birth weight over time is largest, as seen in panels a and b of the figure). Specifically, panel dincludes three lines: A line with the average birth weight, without any controls; a second line, labeled "controls 1 ," which plots the decline in birth weight after accounting for possible changes in the age of the mother, whether the baby was delivered by $\mathrm{C}$-section, and whether the birth is a multiple birth; and a third line, labeled "controls 2," which, in addition, controls for prematurity. A comparison of the three lines in the figure shows that, once prematurity is controlled for, the proportion of low birth weight babies born to mothers with tertiary education declines over time, by about 1 percentage point. In other words, the decline in birth weight for babies born to high-education mothers that is observed in Colombia between 1998 and 2008 can be fully accounted for by an increase in the proportion of births that are premature.

Birth weight is not the only measure of a newborn's health. Attending physicians or nurses also assess the newborn's heart rate, respiratory effort, muscle tone, reflex irritability, and color. This is the basis for the calculation of the APGAR score, generally assessed at one and five 
minutes after birth. The APGAR score ranges from 0 to 10. APGAR scores of 7 or higher are generally an indication that a newborn's health is good. Newborns with a score of 6 or lower, on the other hand, are substantially more likely to die in the neonatal period. This is the case even when the comparison is limited to babies of the same gestational age (Casey, McIntire, and Leveno 2001). Furthermore, using data from the United States, Almond, Chay, and Lee (2005) show that, controlling for family background and birth weight, low APGAR scores also predict poor health, lower cognitive ability, and an increase in behavioral problems at age 3 .

For two years, 2008 and 2009, the vital registration data for Colombia includes a newborn's APGAR score. About 1 percent of newborns have an APGAR score of 6 or below at five minutes after birth. Babies born to women with only primary school education are significantly more likely to have an APGAR score of 6 or below than those born to women with university education (a difference of 0.18 percentage points), once gestational age and birth weight are controlled for. In sum, in Colombia, substantial inequalities can already be observed at birth. In some cases, as with birth weight, babies born to low-education women have better outcomes, while in others, as with the APGAR score, they have worse outcomes.

After birth, the most obvious measure of child welfare is also a tragic one: whether a child dies early on. The "infant mortality rate" is defined as the number of children who die before their first birthday, per 1,000 live births. Figure 2.1 summarizes changes in infant mortality between 1960 and 2010 for six countries that are broadly representative of what has occurred in the region: Brazil, Chile, El Salvador, Honduras, Jamaica, and Panama. Each panel corresponds to a different country. Each bar in a panel represents the infant mortality rate of that country in a given year. As with many social outcomes, it is useful to benchmark a country's performance relative to other countries with similar income levels. For example, was infant mortality in Brazil in 2010 higher, lower, or roughly the same as that of other countries with comparable income levels? To get a sense of this, next to each bar, a circle that represents the average infant mortality rate of all countries with a similar per capita GDP in that year is included (see Box 2.3 for methodological details). ${ }^{3}$ 
Figure 2.1 Infant Mortality per 1,000 Live Births

a. Brazil

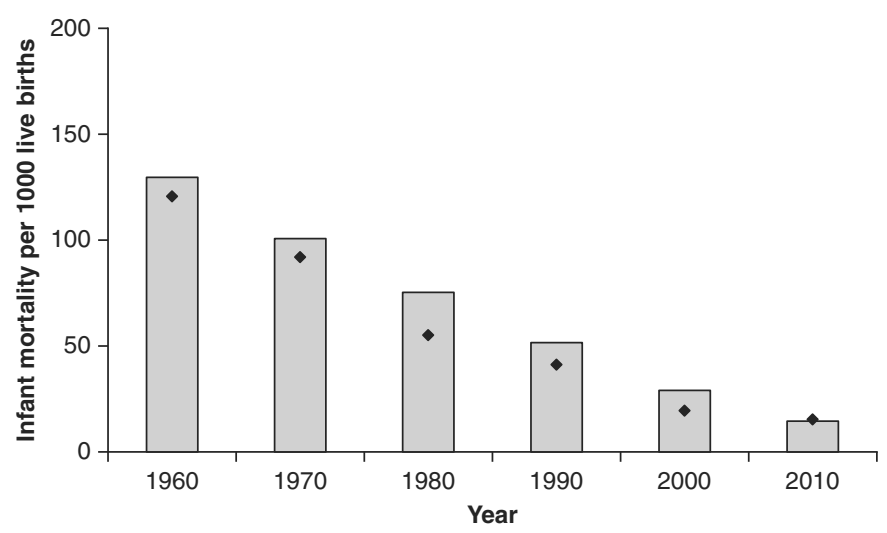

b. Chile

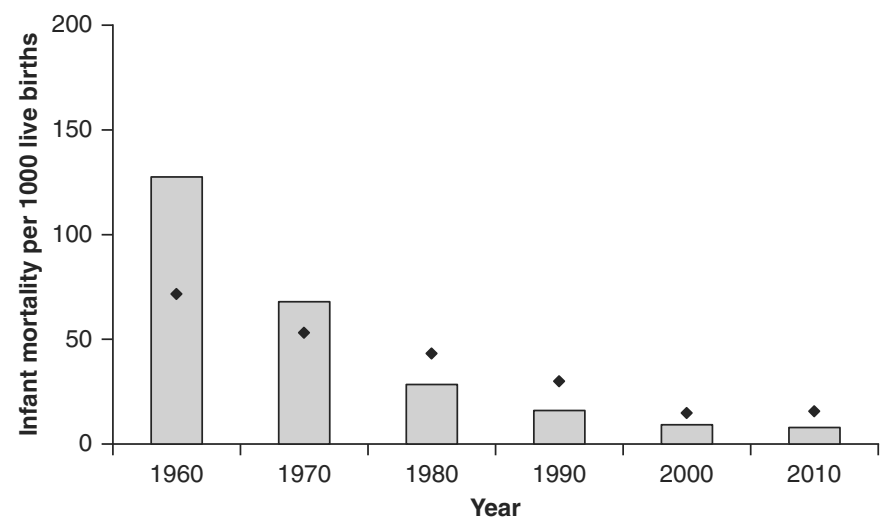

c. El Salvador

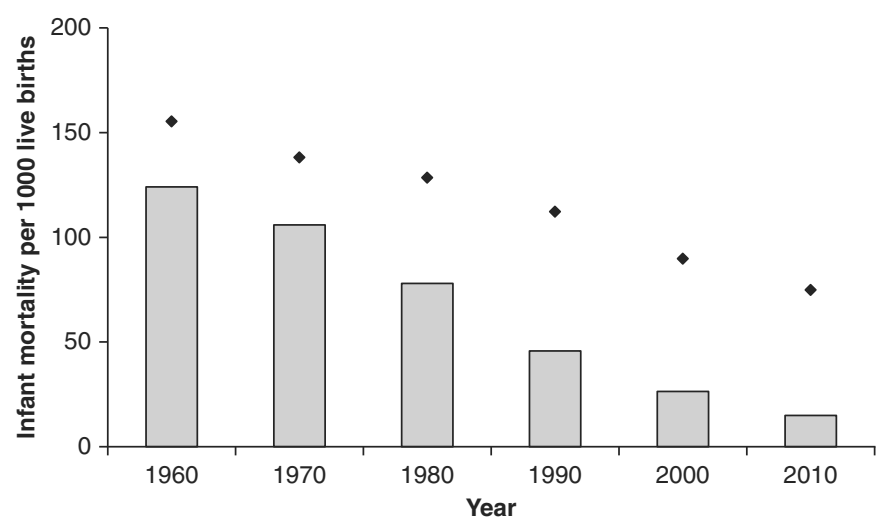




\section{d. Honduras}

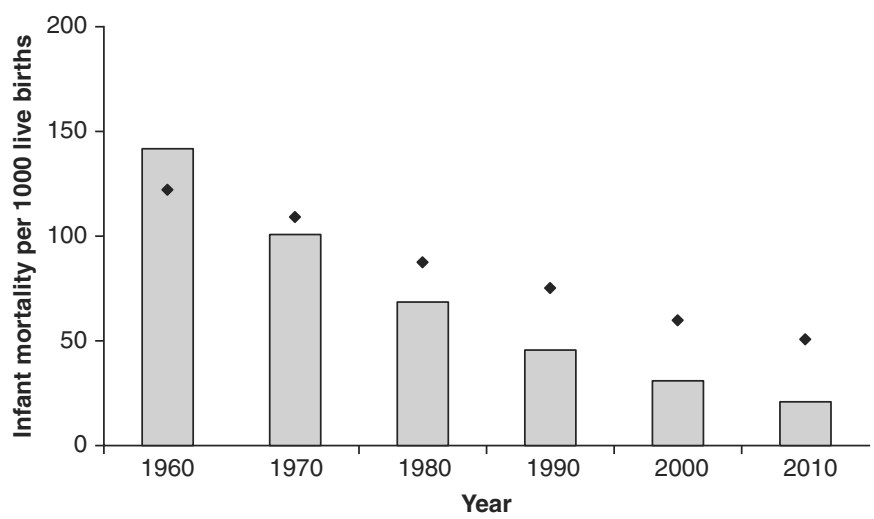

\section{e. Jamaica}

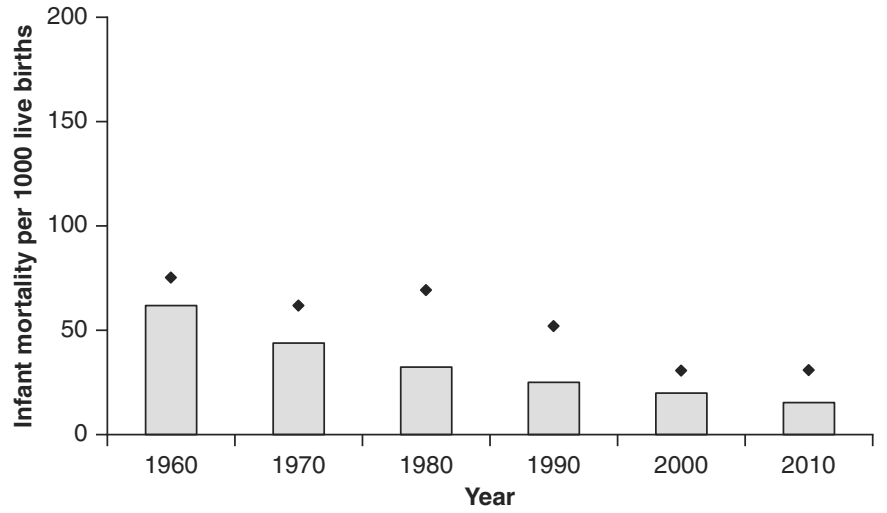

\section{f. Panama}

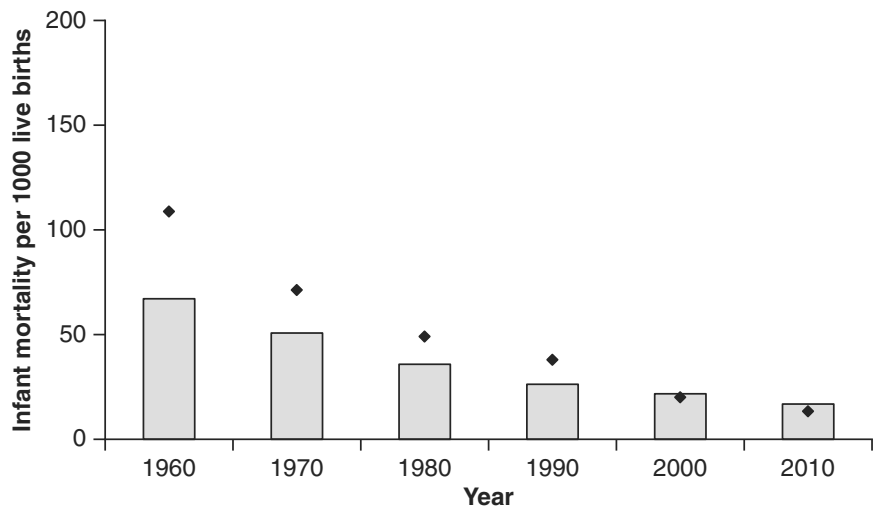

Source: World Development Indicators, Infant mortality rate (per 1,000 live births). Estimates developed by the UN Inter-agency Group for Child Mortality Estimation (UNICEF, WHO, World Bank, UN DESA Population Division). All values of GDP in PPP thousands of dollars (2005 International \$) were taken from the Penn World Table. 


\section{Box 2.3 The Evolution of Infant Mortality Rates and Per Capita GDP}

To see how the relationship between mortality and per capita GDP has evolved over time, nonparametric regressions of the infant mortality rate on GDP per capita were run, separately by decade, for a balanced panel of 79 countries for which these data are available for all six decades. Minor adjustments were made to the regression lines to ensure that the average difference between the observed mortality (the country points) and the predicted mortality (the regression line) is zero in every decade.

It is important to run these regressions separately by decade because medical technology, vaccinations, other public health measures (such as oral rehydration therapy) and the extension of clean water and sanitation all mean that infant mortality is lower in later decades at a given level of GDP. That is, in addition to movements along the curve (as the income of a country grows or, in some cases, contracts), there are downward shifts of the curves themselves over time.

Figure B2.2 focuses on one country, Honduras, which has made remarkable progress in reducing infant mortality. Each line corresponds to the relationship between the infant mortality rate and per capita GDP

\section{Figure B2.2 Infant Mortality Rate and Per Capita GDP, Honduras,} 1960-2010

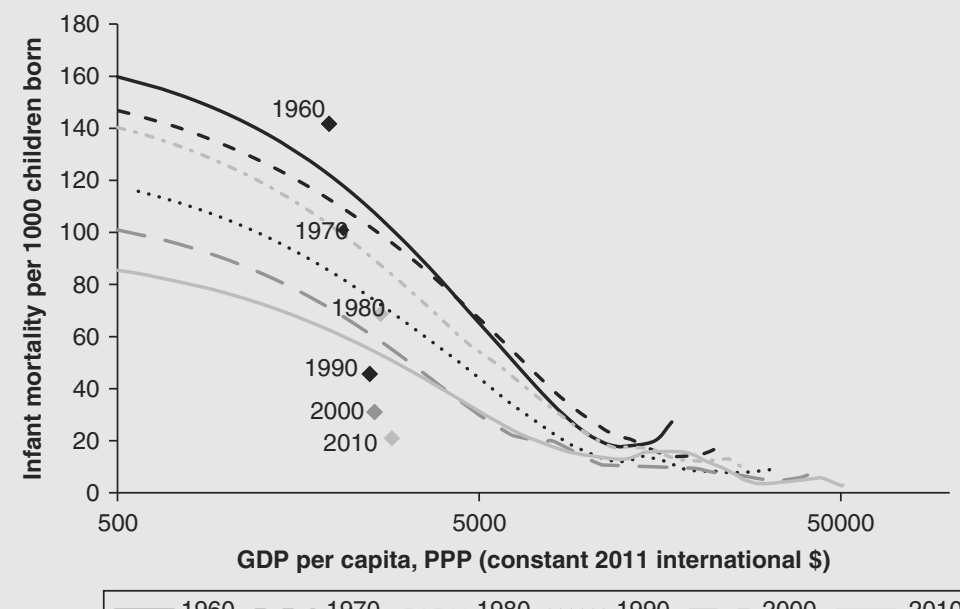

Source: World Development Indicators. Estimates developed by the UN Inter-Agency Group for Child Mortality Estimation (UNICEF, WHO, World Bank, UN DESA Population Division). All values of GDP in PPP thousands of dollars (2005 International \$) were taken from the Penn World Table. 
in a given year, and the points on the graph correspond to infant mortality in Honduras in those same years. The average infant mortality rate has fallen dramatically since 1960, especially at low income levels: A country with a per capita GDP level of $\$ 1,000$ would, on average, have an infant mortality rate of 145 per 1,000 in 1960 but 80 per 1,000 in 2010. In 1960, Honduras had an infant mortality rate that was roughly 20 points above the level predicted by its GDP per capita. Since then, infant mortality in Honduras has fallen to levels that are considerably lower than those of other countries with similar income levels-in 2010, the infant mortality rate in Honduras was roughly 25 points below the regression line.

Infant mortality has declined dramatically in every country in the region. Over a 50-year period, 15 of the 17 countries in Latin America and the Caribbean with available data reduced infant mortality by 75 percent or more; three countries-Brazil, Chile, and Perureduced infant mortality by 90 percent or more. ${ }^{4}$ Some countries, like Brazil, have had infant mortality rates that are roughly comparable to other countries with similar income levels throughout ${ }^{5}$; other countries, like El Salvador and Jamaica, have had lower mortality than other countries with similar income levels for the entire period $^{6}$; yet other countries, like Chile and Honduras, have gone from having a mortality "surplus" to a mortality "deficit"; finally, a few countries, like Panama, have moved in the other direction and now have excess infant mortality. ${ }^{8}$

To study socioeconomic gradients in mortality, it is necessary to work with household survey (rather than aggregate) data. The Demographic and Health Surveys (DHS) are nationally representative surveys of women of childbearing age that can be used to calculate a time series of the infant mortality rate (including among subgroups of the population), under some assumptions. ${ }^{9}$ Table 2.2 summarizes differences in infant mortality for women of "high" education (complete secondary education or more) and "low" education (incomplete primary education or less) for countries that have recently fielded a DHS. It shows that, in the Dominican Republic, children born to low-education mothers are four times as likely to die in their first year as those born to high-education mothers; 
Table 2.2 Infant Mortality Rate by Mother's Education

\begin{tabular}{lcc}
\hline Country & $\begin{array}{c}\text { Incomplete } \\
\text { primary or less }\end{array}$ & $\begin{array}{c}\text { Completed } \\
\text { secondary or more }\end{array}$ \\
\hline Bolivia (2004) & 50.5 & 23.5 \\
Colombia (2006) & 23.8 & 12.5 \\
Dominican Republic (2003) & 39.9 & 11.1 \\
El Salvador (2004) & 13 & 10 \\
Honduras (2008) & 16.8 & 11.2 \\
Peru (2008) & 16.8 & 12.8 \\
\hline
\end{tabular}

Note: Restricted to mothers between 25 and 37 years of age at the time of childbirth; five-year moving average; averages calculated for cells with at least 100 births.

Source: Demographic and Health Surveys (DHS), except for El Salvador; Encuesta Nacional de Salud Familiar (FESAL, 2008) for El Salvador.

in Bolivia and Colombia, children of low-education mothers are twice as likely to die in their first year. Maternal education gradients are much more modest in El Salvador, Honduras, and Peru.

To look further at within-country patterns in the evolution of infant mortality, an in-depth analysis of one country in the region, Peru, was carried out. Peru is an interesting case study of changes in infant mortality for a variety of reasons. First, it has collected highquality DHS data since the mid-1980s. Second, it started off with very large disparities in infant mortality by (among other factors) place of residence, socioeconomic status, and ethnicity. An important question is whether the aggregate reductions in infant mortality in Peru were accompanied by a decline in within-country disparities.

Figure 2.2 analyzes the evolution of infant mortality for four population breakdowns. Panel a compares changes in infant mortality for women of "high" education (complete secondary or more) and "low" education (incomplete primary or less). In 1982, the infant mortality rate for children born to low-education mothers was more than twice as high as that for children born to high-education mothers (105 versus 50 deaths per 1,000 live births); by 2008, the infant mortality rate had declined to below 20 per 1,000 for both groups. This means that, over roughly a 25 -year period, infant mortality for children born to women with incomplete primary education or less declined by more than 80 percent, which is equivalent to declines of more than 3 percent per year. 
Figure 2.2 Population Breakdown of Infant Mortality, Peru a. Infant Mortality by Mother's Education

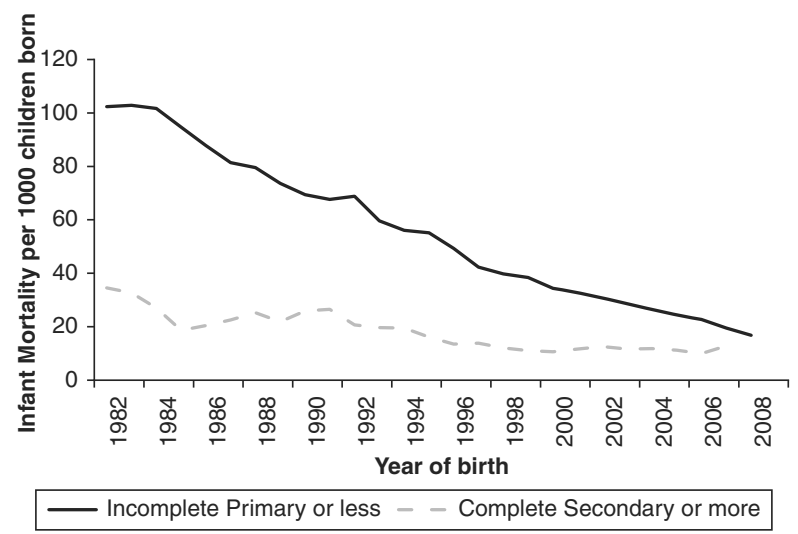

b. Infant Mortality by Mother's Ethnicity

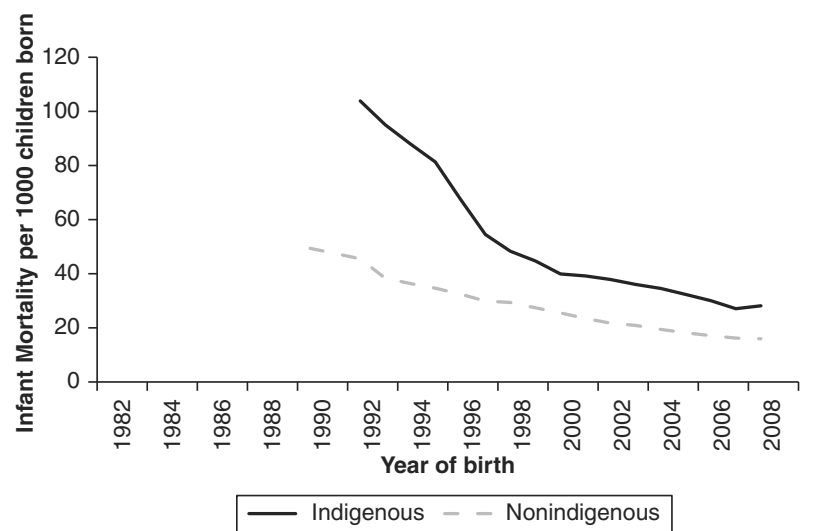

c. Infant Mortality by Mother's Age

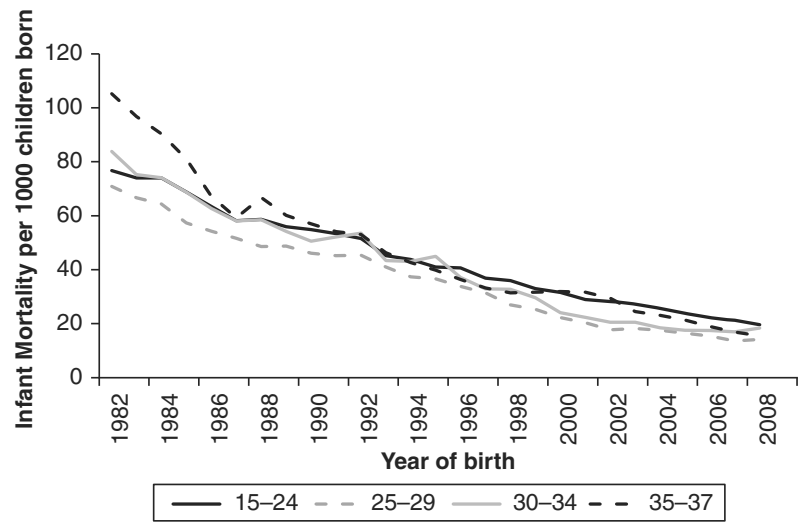




\section{d. Infant Mortality by Infant's Gender}

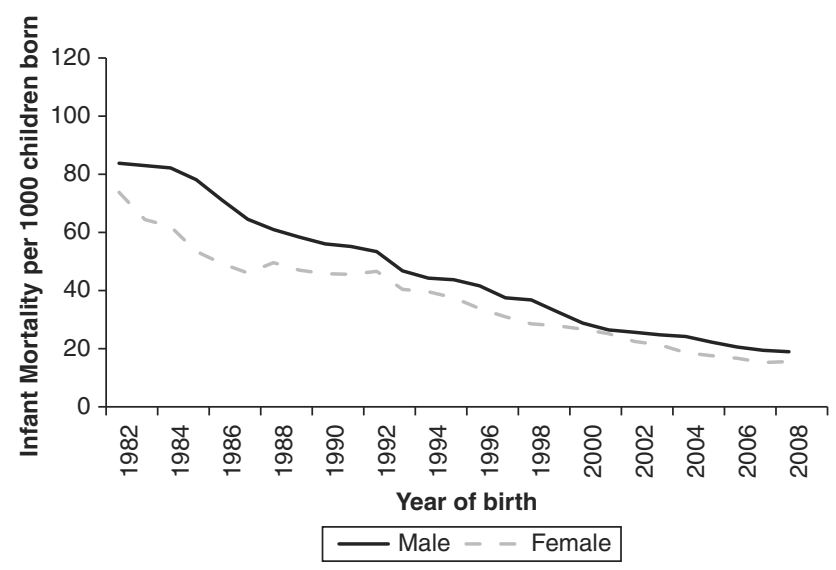

Note: Restricted to mothers between 15 and 37 years of age at the time of birth for panels b, c, and d, and to women 25-37 for panel a. 5-year moving average;, averages calculated for years with at least 100 births. For the ethnicity graph, the 1986, 1991 and 1996 DHS are excluded because data were not collected on ethnicity.

Source: Demographic and Health Surveys (DHS).

Panel $\mathrm{b}$ shows trends in the infant mortality rate for indigenous and nonindigenous mothers. (Ethnicity in Peru is defined on the basis of the respondent's mother tongue.) Data on ethnicity have been collected only in more recent surveys in Peru, so this time series can be constructed only from 1990 onward. The panel shows a dramatic reduction in infant mortality among the indigenous, especially in the 1990s. Between 1991 and 2008, a period of less than 20 years, the infant mortality rate of indigenous children fell by 75 percent-from approximately 100 deaths per 1,000 children born to 25 deaths. ${ }^{10}$ To put the magnitude of these reductions in context, it is informative to compare them with declines in infant mortality among African Americans in the United States. It took the United States roughly 50 years, from 1935 to 1985, to reduce the infant mortality rate among African Americans from 80 to 25 deaths per 1,000 (Singh and van Dyck 2010); the same approximate reduction in the infant mortality rate among the indigenous in Peru was accomplished in less than 15 years, between 1995 and 2008.

Panel $\mathrm{c}$ shows that the reduction in infant mortality has affected mothers in all age groups, including younger mothers (whose children 
had substantially higher mortality rates in the first half of the 1980s, but not since then). Panel d shows that the infant mortality rate has fallen for boys and girls in more or less equal measure. ${ }^{11}$

In Peru, as in many other countries in Latin America and the Caribbean, the average age at which mothers have children has increased, total fertility has been falling, and births are more widely spaced, on average. To see how this might affect mortality, the observed changes in infant mortality can be broken down into changes in the characteristics of mothers and births, changes in the impacts of these characteristics on mortality rates, and an unexplained residual. ${ }^{12}$ The results from these decompositions indicate that changes in characteristics, including the age of the mother, the number of older siblings a child has at birth, the number of months that separate her birth from the previous one, and whether the birth was a singleton or a multiple birth, account for only 7 percent of the decline in the infant mortality rate between the early 1980s and late 2000s in Peru. In other words, the changes associated with the demographic transition cannot by themselves explain much of the decline in infant mortality in Peru. ${ }^{13}$

Next, consider child height. Child height is important because although some children in any population will obviously be taller than others for genetic reasons, when the average stature of children in a population is low, it likely reflects a poor diet or frequent infections in childhood (including inflammation from asymptomatic infections, a phenomenon known as environmental enteropathy). This, in turn, can result in impaired cognitive development and, eventually, worse school outcomes, lower wages, and worse health status over the life cycle, including a higher incidence of chronic diseases in old age. ${ }^{14}$

Data on the height of young children have been collected regularly in many developing countries since the 1990s, including countries in Latin America and the Caribbean. Analysis of these data reveals large differences in the average stature of children in the region: A 4-year-old child is on average six centimeters taller in Chile than in Ecuador, and ten centimeters taller in Chile than in Guatemala. ${ }^{15}$ Children have grown taller in some countries (in Honduras, Nicaragua, and Peru, 4-year-old children were on average two centimeters taller in 2012 than in 2000-01) but not in all (in 
Panama, children were no taller in 2008 than in 1997, on average). ${ }^{16}$ Adults, too, have generally been getting taller in Latin America, although, much as is the case with children, the degree to which this has occurred varies substantially across countries (see Box 2.4).

\section{Box 2.4 Changes in Adult Stature}

A number of economists, including the Nobel Prize winner Robert Fogel and Angus Deaton, as well as many nutritionists, including Reynaldo Martorell and Cesar Victora, have long argued that the average height of a population in adulthood can be a good marker of conditions in early childhood. ${ }^{17}$ Historically, as nutrition has improved and childhood diseases have become much less prevalent, people have become much taller. For example, Deaton (2013) shows that European males have grown by roughly 1 centimeter per decade for over a century, so that the average male born in the 1980s is 12 centimeters taller than one who was born in 1860. Deaton also shows that in China, men and women are growing at roughly 1 centimeter per decade, while in India, men are growing at only half a centimeter per decade and women are growing at less than 0.2 centimeters per decade. He argues that Indians are short, and have been growing little over time, for a variety of reasons, including monotonous diets lacking in protein and fat, inadequate access to clean water, and poor sanitation. India has one of the highest rates of open defecation in the world and this, combined with high population density, results in a very poor disease environment. The preferential treatment of boys over girls in India likely accounts for the difference in their growth rates.

What about the height of adults in Latin America? The stature of adult women is measured in many of the surveys that are used to measure maternal and child health in the region, including the DHS. These data can be used to compare the stature of adult women across birth cohorts. ${ }^{18}$ On average, across ten countries in the region where these data are available, women born in 1990 are about 2 centimeters taller than those born in 1960. However, this average hides important differences. In two countries, Brazil and Chile, women have on average been growing by more than 1.5 centimeters per decade, while in another six-Bolivia, the Dominican Republic, Guatemala, Haiti, Honduras, and Peru-women have been growing taller much more slowly, at less than 0.5 centimeters per decade. 
Data on child height are also the basis for the calculation of chronic malnutrition. For this purpose, the height of a given child is compared to that of children in a reference population of well-nourished children. ${ }^{19}$ If the height of a child is more than two standard deviations below the mean height of children of the same age and gender in this reference population, he or she is said to be stunted, or chronically malnourished. ${ }^{20}$

Figure 2.3 shows changes in chronic malnutrition for six countries that are broadly representative of what has occurred in the region: Bolivia, Guatemala, Haiti, Honduras, Mexico, and Paraguay. As in Figure 2.1, each panel includes bars corresponding to chronic

\section{Figure 2.3 Chronic Malnutrition}

a. Bolivia

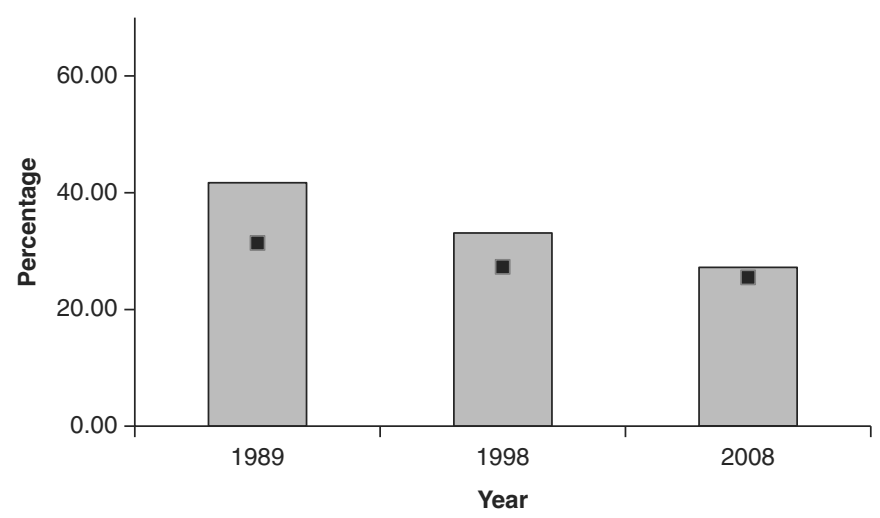

b. Guatemala

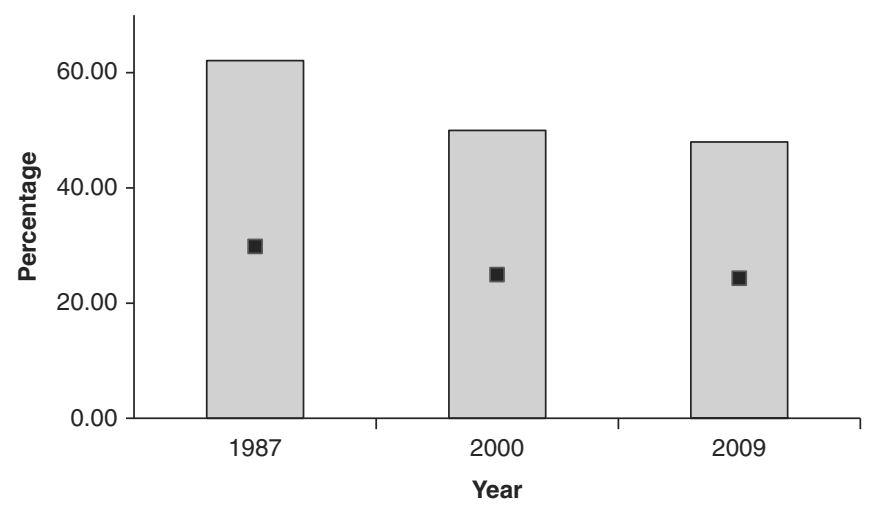




\section{c. Haiti}

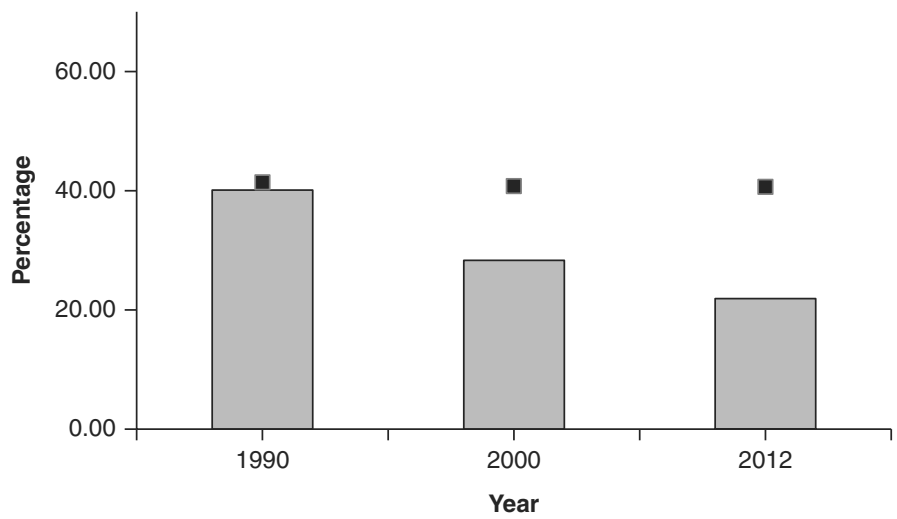

d. Honduras

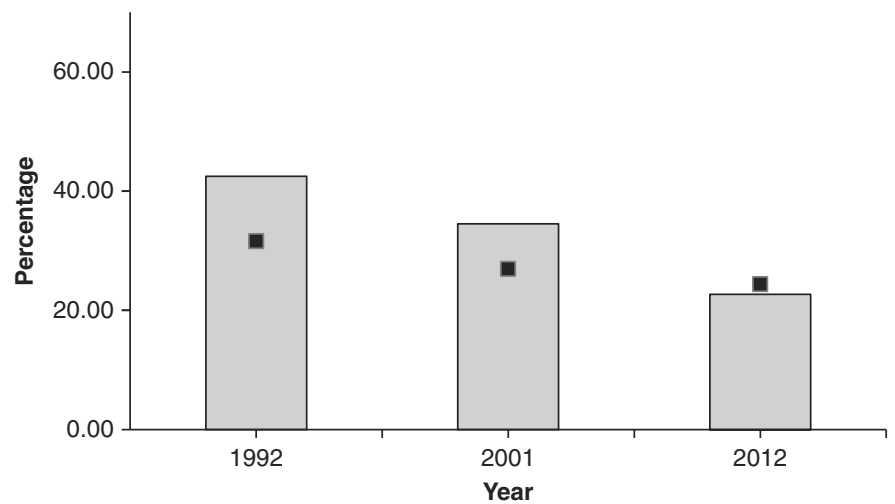

e. Mexico

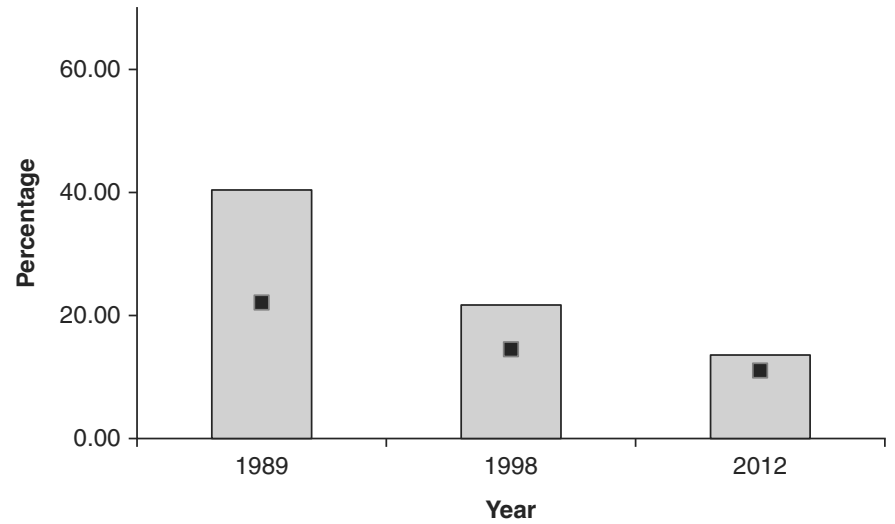




\section{f. Paraguay}

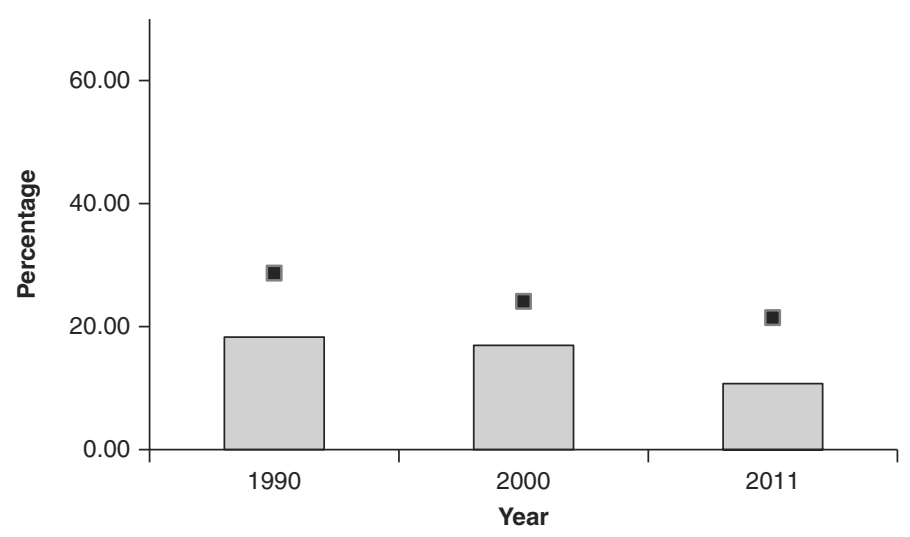

Source: World Development Indicators, World Bank. World Health Organization (WHO). All values of GDP in PPP thousands of dollars (2005 International \$) were taken from the World Economic Outlook Databases (WEO).

malnutrition in a particular country and year, and circles for the average malnutrition in countries of the same income level. However, unlike infant mortality, data on malnutrition are only available beginning in the 1990s or 2000s for most countries, and are not available for exactly the same year in each country.

Many countries in the region have made a good deal of progress reducing stunting rates since the early 1990s. Over a 20-year period, stunting fell by approximately half in ten countries, and by more than 75 percent in Mexico. Most countries in the region now have stunting rates that are roughly comparable to, or substantially lower than, those found in other countries with similar income levels. Only Guatemala, which has one of the highest stunting rates in the world (48 percent), is a clear, negative outlier within the region.

As with infant mortality, it is also informative to look at differences within countries. Table 2.3 compares stunting rates for children of mothers with "low" education (incomplete primary education or less) and those of "high" education (complete secondary education or more) in 19 countries in the region. It shows that maternal education gradients are modest in some countries with overall low stunting rates, including in Brazil, Chile, and Trinidad and Tobago. In other countries, however, including Guatemala, Haiti, and Panama, 
Table 2.3 Chronic Malnutrition, by Mother's Education

\begin{tabular}{lcc}
\hline & \multicolumn{2}{c}{ Stunting } \\
\cline { 2 - 3 } Country & $\begin{array}{c}\text { Incomplete } \\
\text { primary or less }\end{array}$ & $\begin{array}{c}\text { Completed } \\
\text { secondary or more }\end{array}$ \\
\hline Belize (2011) & 24.6 & 10.5 \\
Bolivia (2008) & 36.7 & 11.8 \\
Brazil (2009) & 11.3 & 8.9 \\
Chile (2012) & 2.9 & 2.7 \\
Colombia (2010) & 20.9 & 8.6 \\
Dominican Republic (2007) & 13.7 & 7.4 \\
Ecuador (2012) & 39.6 & 18.3 \\
El Salvador (2008) & 26.5 & 11.8 \\
Guatemala (2008) & 59.5 & 13.7 \\
Haiti (2012) & 27 & 4.5 \\
Honduras (2012) & 35.8 & 7.5 \\
Jamaica (2010) & - & 6.3 \\
Mexico (2012) & 26.9 & 11.2 \\
Nicaragua (2001) & 34.9 & 8.7 \\
Panama (2008) & 35.1 & 7 \\
Paraguay (2012) & 12.9 & 6.3 \\
Peru (2012) & 37.3 & 8.5 \\
Suriname (2011) & 9 & 5.5 \\
Trinidad and Tobago (1987) & 5.8 & 4.8 \\
\hline
\end{tabular}

Notes: For children aged 0-59 months, except for Chile and Trinidad and Tobago. In Chile, the sample refers to children aged 7-59 months, and in Trinidad and Tobago, the sample refers to children aged 3-36 months.

Source: Authors' calculations based on Demographic and Health Surveys (DHS) for Bolivia, Colombia, Dominican Republic, Haiti, Honduras, Peru, and Trinidad and Tobago; Multiple Indicator Cluster Survey (MICS) for Belize and Suriname; Pesquisa de Orçamentos Familiares (POF) for Brazil; Encuesta Longitudinal de la Primera Infancia (ELPI) for Chile; Encuesta Nacional de Salud y Nutrición (ENSANUT) for Ecuador; Encuesta Nacional de Salud y Nutrición (FESAL) for El Salvador; Encuesta Nacional de Salud Materno Infantil (ENSMI) for Guatemala; Survey of Living Conditions (SLC) for Jamaica; Encuesta Nacional de Salud y Nutrición (ENSANUT) for Mexico; Encuesta Nicaragüense de Demografía y Salud (ENDESA); Encuesta de Niveles de Vida (ENV) for Panama; Encuesta de Ingresos, Gastos y Condiciones de Vida (EIGyCV) for Paraguay.

children of less-educated mothers are more than five times as likely to be stunted as those of highly educated mothers. Also, there is a growing problem with the number of children who are overweight or obese, especially in some countries (including Bolivia, Chile, and Mexico) (see Box 2.5). 


\section{Box 2.5 Growing Weight Problems among Children}

Childhood overweight and obesity is increasingly becoming a concern in a number of countries in Latin America and the Caribbean. Obesity in childhood has immediate consequences for child health and may also result in reduced self-esteem and increased depression. Moreover, between one-third and one-half of obese children become obese adults (Serdula and others [1993] is a review, cited in Rivera and others [2014]). It is well established that overweight and obesity are risk factors for noncommunicable diseases in adulthood, including hypertension, type II diabetes, and cardiovascular diseases, among others.

A recent review by Rivera and his coauthors (2014) finds that the proportion of children under the age of 5 who are overweight has increased in a number of countries in Latin America. In Mexico, for example, the proportion overweight in this age group increased from 7.8 to 9.8 percent between 1988 and 2012. ${ }^{22}$

Table B2.1 focuses on the proportion of children under the age of 5 who are overweight or obese, by country, and by maternal education. It shows that the proportion overweight varies a great deal by country, from 3.6 percent in Haiti to 10.1 percent in Chile. In most countries, the rates of overweight and obesity are higher among children of mothers with more education. For example, in Colombia, 2.7 percent of children of "low"-education mothers are overweight, compared with 6.2 percent for children of "high"-education mothers; and in Peru, 0.8 percent of children of low-education mothers are obese, compared with 2.7 percent of children of high-education mothers.

Table B2.1 Overweight and Obesity by Mother's Education

\begin{tabular}{|c|c|c|c|c|c|}
\hline \multirow[b]{2}{*}{ Country } & \multirow{2}{*}{$\begin{array}{c}\text { Prevalence } \\
\text { of overweight } \\
\text { (\% of children } \\
\text { under } 5 \text { ) }\end{array}$} & \multicolumn{2}{|c|}{ Overweight } & \multicolumn{2}{|c|}{ Obesity } \\
\hline & & $\begin{array}{l}\text { Incomplete } \\
\text { primary } \\
\text { or less }\end{array}$ & $\begin{array}{c}\text { Completed } \\
\text { secondary } \\
\text { or more }\end{array}$ & $\begin{array}{c}\text { Incomplete } \\
\text { primary } \\
\text { or less }\end{array}$ & $\begin{array}{c}\text { Completed } \\
\text { secondary } \\
\text { or more }\end{array}$ \\
\hline Belize (2011) & 7.9 & 6.5 & 10 & 2.6 & 3.8 \\
\hline Bolivia (2008) & 8.7 & 8.3 & 10.2 & 1.8 & 2.4 \\
\hline Brazil (2007) & 7.3 & - & - & - & - \\
\hline Chile (2013) & 10.1 & - & - & - & - \\
\hline Colombia (2010) & 4.8 & 2.7 & 6.2 & 0.3 & 1.5 \\
\hline $\begin{array}{l}\text { Dominican } \\
\text { Republic (2007) }\end{array}$ & 8.3 & 6.8 & 8.9 & 1.4 & 2.1 \\
\hline
\end{tabular}




\section{Table B2.1 Continued}

\begin{tabular}{|c|c|c|c|c|c|}
\hline \multirow[b]{2}{*}{ Country } & \multirow{2}{*}{$\begin{array}{l}\text { Prevalence } \\
\text { of overweight } \\
\text { (\% of children } \\
\text { under } 5 \text { ) }\end{array}$} & \multicolumn{2}{|c|}{ Overweight } & \multicolumn{2}{|c|}{ Obesity } \\
\hline & & $\begin{array}{c}\text { Incomplete } \\
\text { primary } \\
\text { or less }\end{array}$ & $\begin{array}{c}\text { Completed } \\
\text { secondary } \\
\text { or more }\end{array}$ & $\begin{array}{c}\text { Incomplete } \\
\text { primary } \\
\text { or less }\end{array}$ & $\begin{array}{c}\text { Completed } \\
\text { secondary } \\
\text { or more }\end{array}$ \\
\hline Ecuador (2012) & 7.5 & 7.8 & 7.8 & 1.5 & 2.9 \\
\hline El Salvador (2008) & 5.7 & 4.2 & 9.5 & 0.7 & 1.8 \\
\hline Guatemala (2009) & 4.9 & - & - & - & - \\
\hline Haiti (2012) & 3.6 & 3.5 & 7.1 & 0.8 & 0.9 \\
\hline Honduras (2012) & 5.2 & 2.9 & 9.8 & 0.8 & 3.2 \\
\hline Jamaica (2010) & 4 & - & 3.5 & - & 1.5 \\
\hline Mexico (2012) & 9 & 8.3 & 9.5 & 2.7 & 2.1 \\
\hline Nicaragua (2006) & 6.2 & - & - & - & - \\
\hline Panama (1997) & 6.2 & - & - & - & - \\
\hline Paraguay (2005) & 7.1 & - & - & - & - \\
\hline Peru (2012) & 7.2 & 3.9 & 10.3 & 0.8 & 2.7 \\
\hline Suriname (2010) & 4 & - & - & - & - \\
\hline $\begin{array}{l}\text { Trinidad and } \\
\text { Tobago (1987) }\end{array}$ & 4 & - & 5.5 & - & 1 \\
\hline
\end{tabular}

Notes: For children aged 0-59 months, except for Chile and Trinidad and Tobago. In Chile, the sample refers to children aged 7-59 months, and in Trinidad and Tobago, the sample refers to children aged 3-36 months.

Source: World Development Indicators (WDI) for prevalence of overweight (\% of children under 5). For overweight and obesity by mother's education, the values reported are from own calculations based on Multiple Indicator Cluster Survey (MICS) for Belize; Demographic and Health Surveys (DHS) for Bolivia, Colombia, the Dominican Republic, Haiti, Honduras, Trinidad and Tobago, and Peru; Jamaica Survey of Living Conditions (JSLC) for Jamaica; Encuesta Nacional de Salud y Nutrición (ENSANUT) for Mexico; and Encuesta Nacional de Salud Familiar (FESAL) for El Salvador.

In sum, countries in Latin America and the Caribbean have made a great deal of progress in improving child health. The proportion of babies who are born with low birth weight is lower than in other developing regions. Also, the region has substantially reduced infant mortality and chronic malnutrition. Some simple statistics summarize the magnitude of the changes that have occurred in the past two decades. In each of three years, 1990, 2000, and 2010, roughly 10 million children were born in Latin America and the Caribbean. ${ }^{21}$ Of these, 428,000 died before their first birthday in 1990, 270,000 in 2000, and 149,000 in 2010. Over a 20-year period, the likelihood that a child born in the region would die in her first year of life fell by 
almost two-thirds. ${ }^{23}$ Similarly, in each of these three years, roughly 50 million children were under the age of five in Latin America and the Caribbean. ${ }^{24}$ Of these 50 million children, 13.7 million were stunted in 1990, 10.2 million were stunted in 2000, and 7.5 million were stunted in 2010. Over a 20-year period, the likelihood that a child under the age of 5 in the region would be chronically malnourished has fallen by almost half. Despite these improvements, however, substantial socioeconomic gradients in infant mortality and, in particular, chronic malnutrition, persist in many countries.

\section{The Gap between Rich and Poor: Cognitive, Language, Socioemotional, and Motor Development}

In addition to health and nutrition, child development encompasses cognitive, language, socioemotional, and motor development (gross and fine). Data on these dimensions of child development have not been collected for nationally representative samples of children in a way that is comparable across countries and available at more than one point in time. ${ }^{25}$ Indeed, there is no agreement on what is the "best" or even an "adequate" measure of language, cognitive, motor, or socioemotional development (see Box 1.4 in Chapter 1). ${ }^{26}$ In practice, different researchers have used different instruments to measure these aspects of child development in the region. ${ }^{27}$ In addition, there is no agreement about how to standardize the scores (see Box 2.6).

\section{Box 2.6 The Debate over Standardization of Scores}

In the literature on child development, there is a debate about whether it is preferable to use external or internal standardization to turn raw scores on a given test into measures that can be compared across children of different ages.

In external standardization, a table is used to convert raw measures into age-standardized scores. For example, the WHO Multicentre Growth Reference Study Group (2006) developed revised "growth tables." These tables, which are based on a sample of approximately 8,500 children in Brazil, Ghana, India, Norway, Oman, and the United States, are used to transform the height and weight of children at a given 
age into standardized z-scores. These z-scores, in turn, are the basis for the calculation of chronic malnutrition (stunting) and acute malnutrition (wasting) for populations all over the world.

No such consensus exists with regard to child language, cognitive, socioemotional, and motor development. Many tests include a table provided by the test developer to convert raw scores into age-standardized scores. However, the sample of children that was used to norm a test is often small. There is also a concern that the norms may not be culturally appropriate in some settings. For example, the TVIP (Test de Vocabulario en Imágenes Peabody), the Spanish-speaking version of the PPVT (Peabody Picture Vocabulary Test), a test that is widely used in evaluations in Latin America, was normed on relatively small samples of children of Mexican immigrants into the United States and on Puerto Rican children (1,219 and 1,488 individuals, respectively).

Internal standardization is an alternative approach. In internal standardization, a given raw score is normalized by subtracting the mean of children of the same age in the population where the test was applied, and dividing by the standard deviation of scores of children of the same age. This is often thought to be a more conservative approach because it does not rely on children from a different population. However, internal standardization makes it impossible to compare the scores of children from different samples - for example, to compare the language scores of children in Chile and Peru. Moreover, in dividing through by the standard deviation, a researcher is implicitly assuming that the observed standard deviation is a good measure of the true standard deviation or, at least, that the difference between the true and observed values is the same for children of different ages.

Unfortunately, this assumption may not always hold. When internal standardization is used, measurement error in child development will result in estimated socioeconomic gradients that are smaller than the true gradients. Suppose there is more measurement error in test scores for very young children-for example, because these children have more difficulty understanding a test, or the scores at these ages reflect a combination of tasks carried out by the children themselves (and observed by the enumerator) and reports from mothers. Under this circumstance, a researcher using internally standardized scores might conclude that socioeconomic gradients increase as children age-even though this could simply be a result of the correlation between measurement error and child age. Ultimately, the choice between external and internal standardization is not easy, and involves making a judgment call about the importance of various measurement problems. 
The fact that child development specialists have not agreed on an appropriate test to measure the cognitive, language, socioemotional, and motor development of young children, and an appropriate reference population to transform raw scores into age-standardized scores, is a serious impediment to the measurement of child development deficits around the world and to the design and evaluation of effective policies.

Differences in the choice of tests and how they are standardized make comparisons across countries difficult. Nevertheless, two recent studies are exceptions. The first, an initiative known as PRIDI (the Spanish acronym for Regional Program of Indicators of Child Development), collected data using the Engle Scale, a new instrument developed for this purpose, on nationally representative samples of approximately 2,000 children in each of four countries: Costa Rica, Nicaragua, Paraguay, and Peru (Verdisco and others 2014). The Engle Scale, which was applied to children aged 24-59 months of age, measures child development in four domains: language and communication, cognitive, motor, and socioemotional development. Overall, comparing children in the richest and poorest quintiles in each country, there are large differences in language development (0.6 standard deviations, on average) and cognition (0.5 standard deviations, on average), and smaller differences in socioemotional development ( 0.3 standard deviations, on average) and motor skills (0.2 standard deviations, on average). ${ }^{28}$ For the cognition and language and communication domains, the wealth gradients appear to increase substantially as children age.

The second study compares performance on the Test de Vocabulario en Imágenes Peabody (TVIP), the Spanish-speaking version of the Peabody Picture Vocabulary Test (PPVT), in the rural areas of five countries: Chile, Colombia, Ecuador, Nicaragua, and Peru (Schady and others 2015). ${ }^{29}$ The TVIP is a measure of receptive vocabulary that has been applied to many samples in Latin America and elsewhere (see Box 2.7); among adults, it is generally considered to be a measure of verbal intelligence. The analysis shows there are steep socioeconomic gradients in TVIP scores in every country, ranging from 0.6 standard deviations in Colombia to 1.2 standard deviations in Ecuador. 


\section{Box 2.7 The Importance of Language}

Many countries in Latin America and the Caribbean, including Chile, Colombia, Ecuador, Mexico, Nicaragua, and Peru, have collected data on receptive vocabulary at early ages using the TVIP (Test de Vocabulario en Imágenes Peabody), the Spanish-speaking version of the PPVT (Peabody Picture Vocabulary Test). The PPVT has been applied extensively in the United States, and translations of the PPVT have been applied in Cambodia, Ethiopia, India, Madagascar, Mozambique, and Vietnam, among other countries. The test has been extensively validated-a long list of references can be found at http://psychology.wikia. com/wiki/Peabody_Picture_Vocabulary_Test.

Early vocabulary has been shown to be strongly predictive of later school performance (Powell and Diamond 2012; Wasik and Newman 2009, among many other cites). Performance on the PPVT at early ages is associated with later school performance in many samples in the United States (Duncan and others 2007; Duncan and Magnuson 2011). Moreover, early vocabulary, as measured by the PPVT and similar tests, is also associated with wages and other labor market outcomes in adulthood in the United States and Great Britain (Case and Paxson 2008; Currie and Thomas 2001).

Schady (2012) uses a panel survey in Ecuador to show that TVIP scores at age 5 years are highly predictive of school performance in early elementary school. A 1 standard deviation increase in TVIP scores at age 5 is associated with 0.32 standard deviation increase in math and language scores three years later, and a decrease of 6.6 percentage points in the probability that a child is a year or more delayed in terms of her grade progression in school. As Schady points out, these associations are likely to be attenuated by measurement error-the "true" association between early vocabulary and school performance in Ecuador is likely to be larger. Although the PPVT and TVIP test only one dimension of early development, receptive language, it is a dimension that seems to be highly predictive of future outcomes.

There are also a number of country-specific studies with data from Colombia, Nicaragua, and Ecuador. These studies differ considerably in the age group of children who were analyzed; in the populations they cover (e.g., in their socioeconomic status); and in the tests that were applied, and how they were standardized. Despite these differences, the results from these studies are broadly consistent. 
Two clear messages emerge. First, children in richer households have higher levels of cognitive and language development. A study of children aged 6-42 months in Bogotá, Colombia, uses the Bayley Scale of Infant Development to analyze gradients (Rubio-Codina and others 2015). The authors find that at age 42 months, children in the 90th percentile of the distribution of wealth have scores that are 0.7 standard deviations higher than those in the 10th percentile in language, and a full standard deviation higher in cognition. The evidence of wealth gradients is much weaker for the other domains of child development (gross and fine motor skills, and socioemotional development).

A study of children between 0 and 71 months of age in rural municipalities in Nicaragua analyzes gradients in a population that is sufficiently poor to be eligible for a targeted cash transfer program (Macours, Schady, and Vakis 2012). The authors apply an amended version of the Denver Developmental Screening Test, which measures four dimensions of child development (language, social-personal, fine motor, and gross motor), as well as a number of other tests for children 3 years and older. They find that the steepest socioeconomic gradients are observed in the language measure of the Denver, and in the TVIP.

Numerous papers study a population that is poor enough to be eligible for a cash transfer program in Ecuador (Paxson and Schady 2007, 2010; Schady 2011, 2012). Steep socioeconomic gradients are found in language, smaller gradients in memory, and no gradients in the incidence of behavior problems. Another study (Araujo and others 2014) uses data on 5-year-old children in the coastal area of Ecuador to analyze socioeconomic differences in executive function, calculated on the basis of tests of memory, attention, cognitive flexibility, and inhibitory control (see Box 1.2 for a definition of executive function). The authors report a difference in executive function of about 0.6 standard deviations between children whose mothers have incomplete primary education or less and those whose mothers have complete secondary education or more.

The second message from these studies is that gradients in cognition and language generally become larger as children age. In Bogotá, at age 18 months, the differences in language and cognition for children at the 10th and 90th percentiles of the distribution of wealth are 
approximately 0.4 standard deviations; at age 42 months, children in the 90th percentile of the distribution of wealth have scores that are 0.7 standard deviations higher than those in the 10th percentile in language, and a full standard deviation higher in cognition (RubioCodina and others 2015). In Ecuador, differences in the TVIP scores between children of mothers who themselves have high and low TVIP scores are modest at age 3 years but substantial at age 5 (Schady 2011). A plausible explanation for this pattern of results is that the effect of low socioeconomic status on child development is cumulative.

Are the patterns observed in the region unusual? In particular, are the socioeconomic gradients in Latin America and the Caribbean larger or smaller than those observed elsewhere? These are not easy questions to answer given the lack of comparability in the measures of child development used in different studies and countries. Nevertheless, some reasonable comparisons can be made, in particular with regard to receptive vocabulary, as the PPVT, its Spanishspeaking version (the TVIP), and translations of the PPVT into various languages have been applied in a number of developing and developed countries.

First, a direct comparison of socioeconomic gradients in receptive language between children in the United States and Ecuador suggests that the differences in vocabulary between richer and poorer households are larger in Ecuador (Paxson and Schady 2007). ${ }^{30}$ Second, data from the Young Lives study suggests that socioeconomic gradients in receptive vocabulary are steeper in Peru than in India, Ethiopia, and Vietnam (López Boo 2014).

In sum, data from a number of studies in Latin America and the Caribbean show that there are substantial differences in child development within countries. Much as has been found in Australia, Canada, the United Kingdom, and the United States (Bradbury and others 2012; Waldfogel and Washbrook 2011), socioeconomic gradients in the region are steepest in language and cognitive development, and much less apparent for other outcomes, including socioemotional development and the incidence of behavioral problems. Differences in language and cognitive development between richer and poorer children appear early, and are generally more pronounced among older children, at least until these children enter the formal schooling system. 


\section{The Total Picture}

What is known about the development of young children in the Latin American and Caribbean region? Overall, the region's children enjoy relatively good health and nutrition, especially when compared with conditions a few decades earlier. The proportion of babies that are born with low birth weight is lower than in other developing regions. Latin America and the Caribbean has made tremendous progress reducing infant mortality. Many countries in the region now have infant mortality rates that are comparable to, or lower than, those found in other countries with similar income levels. Children and adults in the region are becoming taller. A good deal of progress has also been made reducing stunting rates, although chronic malnutrition continues to be a challenge in parts of Central America and the Andean region, particularly among children in poor households and the indigenous.

The picture is less clear with regard to other dimensions of child development. Data are often lacking or are not comparable. Keeping these data limitations in mind, there appear to be steep socioeconomic gradients within countries in language and cognitive development. In contrast, and consistent with what is observed in richer countries outside the region, gradients are much less apparent in motor development (especially gross motor skills), socioemotional development, and the incidence of behavior problems.

Socioeconomic gradients in language and cognition are a concern because they are fundamental aspects of early school readiness. Indeed, panel data from the United States (Duncan and Magnuson 2011; Duncan 2011) and Ecuador (Schady 2012) suggest that children who begin school with adequate levels of early literacy and numeracy are much more likely to succeed in school. In this way, because poorer children in many countries in Latin America and the Caribbean are less likely to be school-ready than their better-off peers, inequality is transmitted from one generation to the next.

cc)(F) Except where otherwise noted, this work is licensed under a Creative Commons Attribution-NonCommercial-NoDerivatives 3.0 IGO License. To view a copy of this license, visit https://creativecommons. org/licenses/by-nc-nd/3.0/igo/ 